\title{
Aortic valve choice in the transcatheter aortic valve replacement era
}

\author{
Scott C. DeRoo, Joseph E. Bavaria \\ Division of Cardiac Surgery, University of Pennsylvania School of Medicine, Philadelphia, PA, USA \\ Correspondence to: Joseph E. Bavaria, MD. Hospital of the University of Pennsylvania, 3400 Spruce Street, Silverstein 6, Philadelphia, PA 19104, USA. \\ Email: Joseph.Bavaria@uphs.upenn.edu.
}

Submitted Oct 13, 2020. Accepted for publication Apr 07, 2021.

doi: 10.21037/acs-2021-tviv-14

View this article at: https://dx.doi.org/10.21037/acs-2021-tviv-14

\section{Introduction}

The advent of transcatheter aortic valve replacement (TAVR) has fundamentally changed the way we think of aortic valve disease. Surgical considerations for an index aortic valve intervention are now informed by the feasibility and optimization of a future transcatheter valvein-valve $(\mathrm{ViV})$ procedure. Over the past decade the number of TAVRs has grown exponentially, and the expanded indication to younger patients promises that these numbers will continue to increase (1). While the longterm durability of transcatheter valves remains unknown, both patient and physician enthusiasm for this therapy has outpaced current guidelines. Despite these surging TAVR numbers, cardiac surgeons continue to perform high numbers of aortic valve replacements. Conditions such as bicuspid aortic valve disease, aortic regurgitation, and endocarditis remain within the realm of the surgeon, as do many cases of aortic stenosis. Therefore, the question remains, how should we as cardiac surgeons think about index surgical valve choice in the modern TAVR era?

Clearly this question has taken on increased importance over the past decade. Traditionally, decisions regarding valve choice were limited to factors such as effective orifice area (EOA), durability and desire for anticoagulation; however, both patients and surgeons are now selecting valves with consideration as to the ease of future $\mathrm{ViV}$ TAVR. Although it seems intuitive that ViV TAVR will offer life-prolonging therapy without the risks inherent to reoperative cardiac surgery, the consequences of this strategy remain largely uninvestigated, especially in younger patients.

Within the past decade, there has been a significant shift away from mechanical aortic valves in favor of bioprosthetic ones (2). Whereas mechanical valves made up one quarter of all implanted surgical aortic valves in 2002, that number had fallen to a mere $12.2 \%$ by 2016 (2). Interestingly, this trend appears to have gained traction prior to the introduction of TAVR and has actually slowed slightly during the height of the TAVR era (2). At the same time, the AHA consensus guidelines have decreased the age at which they feel choosing a bioprosthetic valve is reasonable, with the lower limit of that age cohort now set at 50 years instead of 60 (3). Despite this guideline shift, there is data demonstrating a small but persistent survival advantage for patients $<55$ years old who receive a mechanical valve as opposed to a bioprosthetic (4). As has been stated previously, the shift towards bioprosthetic valves, especially in younger patients, remains non-data driven, and appears to be largely due to a desire on both the part of the physician and the patient to avoid long-term anticoagulation (5). An important caveat is that many of these studies have not been conducted in the TAVR ViV era, and it may be that some observed mortality in these younger patients is due to the consequences of structural valve deterioration and the subsequent morbidity of reoperative surgery. However, despite the burgeoning enthusiasm for bioprosthetic valves, there remain many younger patients who would likely be better served with a mechanical aortic valve. In these patients, a well-chosen mechanical prosthesis offers the greatest chance of complication free-survival.

In addition to the shift in favor of bioprosthetic valves, there has been an increase in the size of bioprostheses being implanted. Several recent studies have demonstrated an increase in the mean manufacturer given valve size as well as the true internal valve diameter over the last two decades $(2,6)$. Interestingly, higher volume centers tended to implant larger sized valves than lower volume centers. With respect 
to future valve-in-valve TAVR, it is important to implant the largest valve size that can be safely accommodated. Previous studies have demonstrated that implantation of a ViV TAVR in an aortic bioprosthesis $\leq 21 \mathrm{~mm}$ results in a significant increase in mortality $(7,8)$. It is therefore important to avoid small valves in patients who may be considered for ViV TAVR in the future so as not to limit their chances of a successful transcatheter procedure. To this end, it may be reasonable to consider root enlargement, or simply root replacement in patients who otherwise would not be able to accommodate a $23 \mathrm{~mm}$ or greater bioprosthetic valve. Additionally, it is increasingly important to pay attention to the location of the coronary ostia in relation to the aortic bioprosthesis. In many instances the intentional placement of an oversized supra-annular valve results in a significant decrease in the distance from the aortic annulus to the coronary ostia. While historically the concern was related only to coronary obstruction, it is now important to consider how coronary position may affect a future $\mathrm{ViV}$ procedure. Although low-riding coronary ostia may have caused little previous concern, such coronaries may limit the ability to pursue future ViV TAVR due to the risk of obstruction after TAVR deployment. As such it is of critical importance that the position of the coronaries be evaluated in relation to the position of the aortic valve leaflets when in a fixed, open position. Will the leaflets directly cover the coronary ostia? Will they rise to the level of the STJ such that they create a total occlusion of the sinus of Valsalva? In such an instance we feel it reasonable to perform aortic root replacement such that the coronaries can be mobilized and reimplanted with sufficient distance from the aortic annulus to allow for future ViV TAVR. Although this is not yet reflected in the guidelines for aortic root replacement, at high-volume aortic centers root replacement likely yields little increase in operative mortality and may spare the patient an open cardiac reoperation.

\section{Conclusions}

In the TAVR era more patients than ever before are choosing bioprosthetic aortic valves. It is important to implant the largest size bioprosthesis possible, ideally $23 \mathrm{~mm}$ or greater, in order to facilitate future valve-in-valve TAVR. Root enlargement or Bentall may be necessary to help facilitate this. It is of critical importance to evaluate the position of the coronary ostia such that future ViV TAVR is feasible without concern for coronary obstruction. In patients less than
50 years old, a mechanical valve may still represent the best option for long-term survival. The recently published Valve guidelines are not recommending Tissue or Mechanical Valves in the fifty to sixty years old patient. We feel very strongly that this group absolutely needs a "patient-centered" approach with complete information and the ability to make their own choices.

\section{Acknowledgments}

Funding: None.

\section{Footnote}

Conflicts of Interest: The authors have no conflicts of interest to declare.

Open Access Statement: This is an Open Access article distributed in accordance with the Creative Commons Attribution-NonCommercial-NoDerivs 4.0 International License (CC BY-NC-ND 4.0), which permits the noncommercial replication and distribution of the article with the strict proviso that no changes or edits are made and the original work is properly cited (including links to both the formal publication through the relevant DOI and the license). See: https://creativecommons.org/licenses/by-nc-nd/4.0/.

\section{References}

1. Carroll JD, Mack MJ, Vemulapalli S, et al. STSACC TVT Registry of Transcatheter Aortic Valve Replacement. Ann Thorac Surg 2021;111:701-22.

2. Tam DY, Rocha RV, Wijeysundera HC, et al. Surgical valve selection in the era of transcatheter aortic valve replacement in the Society of Thoracic Surgeons Database. J Thorac Cardiovasc Surg 2020;159:416-427.e8.

3. Writing Committee Members; Otto CM, Nishimura RA, et al. 2020 ACC/AHA Guideline for the Management of Patients With Valvular Heart Disease:

Executive Summary: A Report of the American College of Cardiology/American Heart Association Joint Committee on Clinical Practice Guidelines. J Am Coll Cardiol 2021;77:450-500.

4. Goldstone AB, Chiu P, Baiocchi M, et al. Mechanical or Biologic Prostheses for Aortic-Valve and Mitral-Valve Replacement. N Engl J Med 2017;377:1847-57.

5. Kurlansky P. Commentary: The future of heart valve 
surgery: Transcutaneous aortic valve replacement and beyond. J Thorac Cardiovasc Surg 2020;159:428-9.

6. Silaschi M, Conradi L, Treede H, et al. Trends in Surgical Aortic Valve Replacement in More Than 3,000 Consecutive Cases in the Era of Transcatheter Aortic Valve Implantations. Thorac Cardiovasc Surg 2016;64:382-9.

7. Dvir D, Webb JG, Bleiziffer S, et al. Transcatheter

Cite this article as: DeRoo SC, Bavaria JE. Aortic valve choice in the transcatheter aortic valve replacement era. Ann Cardiothorac Surg 2021;10(5):683-685. doi: 10.21037/acs-2021tviv-14 aortic valve implantation in failed bioprosthetic surgical valves. JAMA 2014;312:162-70.

8. Webb JG, Murdoch DJ, Alu MC, et al. 3-Year Outcomes After Valve-in-Valve Transcatheter Aortic Valve Replacement for Degenerated Bioprostheses: The PARTNER 2 Registry. J Am Coll Cardiol 2019;73:2647-55. 